\title{
COMPARATIVE SEM EVALUATION OF THREE SOLVENTS USED IN ENDODONTIC RETREATMENT: AN EX VIVO STUDY
}

\author{
Miriam F. Zaccaro SCELZA ${ }^{1}$, Jeffrey M. COIL ${ }^{2}$, Ana Carolina de Carvalho MACIEL ${ }^{3}$, \\ Lílian Rachel L. OLIVEIRA ${ }^{4}$, Pantaleo SCELZA ${ }^{5}$
}

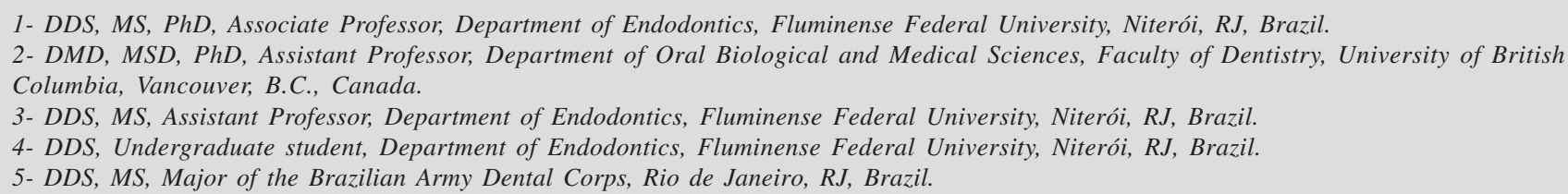

Corresponding address: Miriam F. Zaccaro Scelza - Av. 28 de Setembro, $\mathrm{n}^{\circ} 44$ - sala 704 - Vila Isabel - 20551-031 - Rio de Janeiro, Brazil. Phone: 552122340901 - e-mail: scelza@ terra.com.br

Received: March 24, 2007 - Modification: May 31, 2007 - Accepted: August 15, 2007

\begin{abstract}
This materials from dentinal tubules during endodontic retreatment. Forty human maxillary canines with straight canals were prepared according to a crown-down technique and enlarged to a\#30 apical file size, before obturation with gutta-percha and a zinc-oxide-eugenol based sealer. The samples were stored for 3 months before being randomly assigned to four groups: chloroform $(n=10)$, orange oil $(n=10)$, eucalyptol $(n=10)$ and control $(n=10)$. Solvents were applied to a reservoir created on the coronal root third using Gates Glidden drills. The total time for retreatment using the solvents was 5 minutes per tooth. Following retreatment the roots were split longitudinally for SEM evaluation. SEM images were digitized, analyzed using Image ProPlus 4.5 software, and the number of dentinal tubules free of filling material from the middle and apical thirds was recorded. No significant difference was found among the solvent groups regarding the number of dentinal tubules free of root filling remnants in the middle and apical root thirds $(\mathrm{p}>0.05)$. However, the control group had fewer dentinal tubules free of filling material $(\mathrm{p}<0.05)$. Under the tested conditions, it may be concluded that there was no significant difference among the solvents used to obtain dentinal tubules free of filling material remnants.
\end{abstract}

Uniterms: Chloroform. Orange oil. Eucalyptol. Endodontic retreatment.

\section{INTRODUCTION}

Endodontic retreatment requires removal of pre-existing endodontic filling material and disinfection of the root canal system. This is accomplished during chemomechanical reinstrumentation. In order to remove filling materials without damage to the tooth, chemical solvents are used to solubilise gutta-percha ${ }^{1,2,5}$. Orange oil, eucalyptol, xylol, chloroform, halothane, and rectified turpentine have all been used as adjuncts to remove endodontic filling materials ${ }^{13,15,16,21}$. Retreatment has also been done combining heat with a solvent, in order to remove filling material from thermafilobturated teeth ${ }^{33}$. It has been shown that ultrasonic instrumentation required significantly less time to remove root fillings than hand instrumentation ${ }^{16}$ Others authors have shown that rotary instruments remove more filling materials during endodontic retreatment than manual instruments ${ }^{3,12,17}$.
Additionally, Nd:YAP laser was shown to be effective for root canal preparation during retreatment because it preserves the root canal dentin walls and does not cause temperature raise in the root, which could potentially harm the periodontal tissues ${ }^{7}$. Furthermore, orange oil has been shown not only to be effective ${ }^{11}$, but also to be less cytotoxic than eucalyptol, xylol, chloroform and halothane ${ }^{24}$, during endodontic retreatment procedures.

Studies have reported that it is essential to remove all root canal filling material from anatomic ramifications and dentinal tubules to ensure cleaner root canal walls ${ }^{28}$. This facilitates chemomechanical preparation and antimicrobial dressing to access all ramifications of the entire root canal system during retreatment and decrease the residual microbial population ${ }^{4,6,28,30,32}$. In spite of all different retreatment strategies, studies have shown that it is not possible to obtain root canal walls completely free of debris 
and residual infection ${ }^{14,31}$

The aim of the present study was to evaluate, by scanning electron microscopy (SEM), the efficacy of chloroform, orange oil and eucalyptol as adjuncts during endodontic retreatment on the removal of obturation material from dentinal tubules.

\section{MATERIALAND METHODS}

Forty human maxillary canines were obtained from the tooth bank of the Federal Fluminense University. Teeth with straight roots were selected and then radiographed to ensure that they had a single canal, mature apex and less than 5 degree curvature.

Teeth were sectioned to provide remaining roots measuring $21 \mathrm{~mm}$ in length. Working length was set at 20 $\mathrm{mm}$ and the root canals were prepared using K-files according to a crown-down technique. Instrumentation began with Kfile size 80, and progressively smaller K-files were used to prepare to a final apical size \#30 K-file (Dentsply Maillefer, Ballaigues, Switzerland)

Canals were irrigated with $2 \mathrm{~mL} 5.25 \% \mathrm{NaOCl}$ (Formula \& Ação Farmácia, São Paulo, SP, Brazil) at each change of instrument. When instrumentation was completed, canals were irrigated with $20 \mathrm{~mL} 10 \%$ citric acid (Formula \& Ação Farmácia, São Paulo, SP, Brazil) to remove smear layer, followed by rinsing with $20 \mathrm{~mL}$ distilled water.

The canals were dried with paper points before obturation with gutta-percha and Endofill sealer (Dentsply, Petrópolis, RJ, Brazil). The root canals were obturated using the lateral compaction technique employing standardized gutta-percha master cones (Dentsply, Petrópolis, RJ, Brazil), finger spreaders and accessory cones. Excess gutta percha was removed at the canal entrance with heated instruments, before vertical compaction was used to condense gutta percha at the coronal root third. The coronal access cavities of the specimens were sealed with a temporary filling material (Coltosol; Coltene-Whaledent, Cuyahoga Falls, OH, USA).

Radiographs of each specimen were taken to ensure homogeneity of root canal obturation, lack of voids and proper length of the root canal filling material, before storage at $37^{\circ} \mathrm{C}$ in $100 \%$ humidity (artificial saliva) for 3 months. The teeth were assigned to four groups of ten roots each, according to the solvent employed: Group I: Control (no solvent), Group II: chloroform (Fórmula \& Ação Farmácia de Manipulação, São Paulo, SP), Group III: orange oil (Fórmula \& Ação Farmácia de Manipulação, São Paulo, SP), and Group IV: eucalyptol (Fórmula \& Ação Farmácia de Manipulação, São Paulo, SP). In the control group, the filling material was not removed.

A reservoir for solvents was created within the coronal root third using \#2 $(0.70 \mathrm{~mm})$ and \#3 $(0.09 \mathrm{~mm})$ Gates Glidden drills to a depth of $3 \mathrm{~mm}$ beyond the canal entrance. $0.4 \mathrm{~mL}$ of each solvent was delivered with a syringe to sample reservoirs. After 2 minutes, to allow for solvent penetration, crown-down instrumentation was initiated to remove gutta percha using a size $60 \mathrm{~K}$-file. Every 30 seconds, canal debris was removed by rinsing with $2.0 \mathrm{~mL} 5.25 \% \mathrm{NaOCl}$ using a 30 -gauge irrigation needle, before adding solvent and using sequentially smaller diameter files to remove gutta percha using a reaming motion. The endpoint of instrumentation was determined when a \#30 K-file reached the working length. The total time required to remove the filling material was 5 minutes.

Apical patency was ensured with \#10 K-file before final irrigation with $10 \mathrm{~mL}$ of citric acid and $10 \mathrm{~mL}$ with $5.25 \%$ $\mathrm{NaOCl}$. All canals were then dried with paper points.

Longitudinal grooves were prepared on the external surface of all roots before splitting the samples into two halves. One half of each sample was mounted on an SEM specimen holder before placement in a vacuum chamber and coating with a 20 -nm thick gold-palladium layer. Microscopic analyses were done using a scanning electron microscope (DSM940, ZEISS, Oberkochen, Germany). SEM images were obtained with an acceleration tension of $20 \mathrm{kV}$, in modes of secondary (SE) and back-scattered (BSE) electrons. All sample preparation procedures were performed by the same operator.

For evaluation purposes, each specimen was divided into cervical, middle and apical thirds. A single evaluator, who was blinded to the specimen location, examined only the central region of the middle and apical thirds. SEM micrographs of the center of the middle and apical third regions were taken at X500 magnification that corresponded to an area of $367.2 \mu \mathrm{m}^{2}$. The number of open dentinal tubules per area unit was quantified using image Pro Plus 4.5 software (Media Cybernetics, Silver Spring, MD, USA). The number of dentinal tubules free of filling materials per $\mathrm{mm} 2$ was statistically evaluated by Kruskall-Wallis test $(\mathrm{p}<0.05)$.

\section{RESULTS}

The median of the numbers of dentinal tubules free of filling materials per $\mathrm{mm}^{2}$ is displayed on Table 1. Although there was a tendency for orange oil to yield a larger number of dentinal tubules free of filling material per $\mathrm{mm}^{2}$ compared to chloroform and Eucalyptol, this difference was not statistically significant $(\mathrm{p}<0.05)$ for both the middle and the apical root canal thirds. However, all three tested solvents had significantly more visible dentinal tubules free of filling materials than the control group $(\mathrm{p}<0.05)$.

Figures 1 and 2 represent SEM micrographs of the evaluated areas, in the middle and apical root thirds respectively, showing dentinal tubules free of filling materials after the endodontic retreatment using the tested solvents. White arrows in these figures point to open dentinal tubules. 
TABLE 1- Means of the number of dentinal tubules free of filling materials per $\mathrm{mm}^{2}$ in each group

\begin{tabular}{|c|c|c|c|c|c|}
\hline \multicolumn{2}{|l|}{ Third } & $\begin{array}{l}\text { Control } \\
\text { Mean } \\
\text { (Range) }\end{array}$ & $\begin{array}{l}\text { Chloroform } \\
\text { Mean } \\
\text { (Range) }\end{array}$ & $\begin{array}{l}\text { Orange oil } \\
\text { Mean } \\
\text { (Range) }\end{array}$ & $\begin{array}{l}\text { Eucalyptol } \\
\text { Mean } \\
\text { (Range) }\end{array}$ \\
\hline \multirow{4}{*}{$\begin{array}{l}\text { Number } \\
\text { of tubules }\end{array}$} & Middle & 1332.25 & $6160.46^{*}$ & $6332.35^{\star}$ & $6286.98^{*}$ \\
\hline & & (242) & (2027) & (1335) & (1345) \\
\hline & Apical & 1053.12 & $3552.05^{\star *}$ & $3575.53^{* *}$ & $3501.29^{* *}$ \\
\hline & & (135) & $(876)$ & (1000) & $(946)$ \\
\hline
\end{tabular}

${ }^{*},{ }^{* *}$ : No statistically significant difference $(p>0.05)$ using Kruskall-Wallis test.
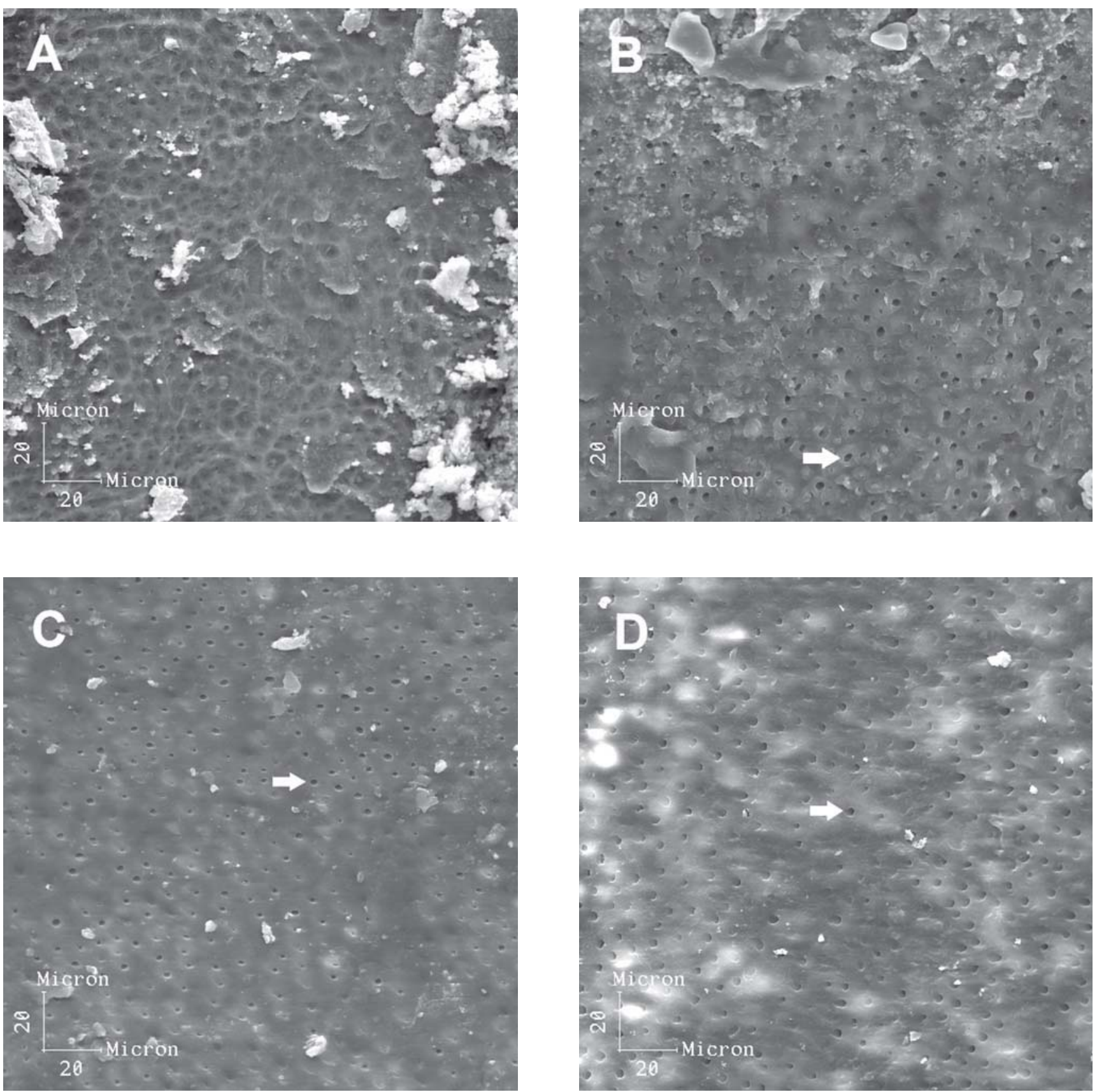

FIGURE 1- Representative SEM micrographs of samples from the middle root third: A) Control, B) Chloroform, C) Eucalyptol, D) Orange oil. Note the presence of only few open dentinal tubules (arrows). Original magnification X500 

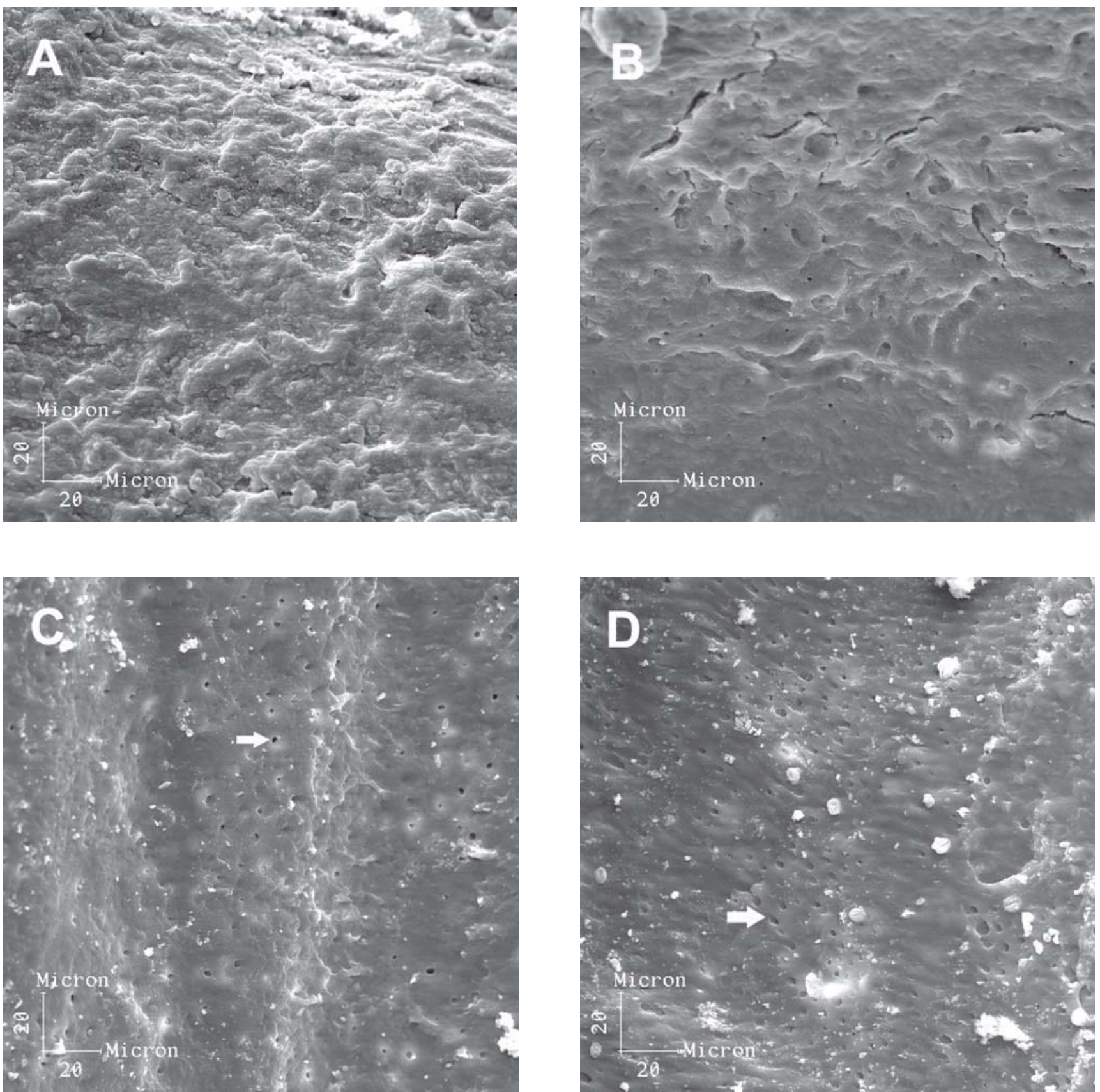

FIGURE 2- Representative SEM micrographs of samples from the apical root third: A) Control, B) Chloroform, C) Eucalyptol, D) Orange oil. Note the presence of only few open dentinal tubules (arrows). Original magnification X500

\section{DISCUSSION}

The retreatment of a previously filled root canal is indicated when there is a persistent periradicular disease resulting from coronal microleakage, incomplete cleaning and shaping, and complex anatomy. Procedures for removal of root fillings include the use of stainless steel hand files, heat, ultrasonic, laser, rotary systems and solvents $2,9,14,22,28,29,31$. In this study, 40 maxillary canines were chosen because of their round anatomic shape, which would facilitate the removal of the filling material.

Complications during retreatment procedures may be accounted for by the resistance of the filling material to instrument penetration ${ }^{8}$. In this context, solvents serve as useful adjuncts to the action of the mechanical action instruments.

Although many endodontic retreatment studies have been reported, little clinical data are available regarding the time required to keep root canals soaked in solvents during retreatment. Removal of gutta-percha using hand files with or without solvent can be time-consuming, especially when the root canal filling material is well condensed ${ }^{20}$ A mean time of 1.5-10.8 minutes have been reported in laboratorial studies for retreatment of canals filled with laterally condensed gutta-percha and sealer ${ }^{6,18,20,30}$. Our study allowed 5 minutes to remove the obturation material. 
In this study, samples were maintained at $100 \%$ humidity at $37^{\circ} \mathrm{C}$ for 3 months to simulate oral conditions $s^{22}$, prior to retreatment. However, studies have used different storage times, ranging from 2 to 3 weeks $^{6,20}$. It is conceivable that different storage methods and length of storage time may affect the cleaning of the root canal system.

The results indicated that there was no significant difference in the number of dentinal tubules free of filling materials among the tested solvents. Our study corroborates the results published elsewhere, which revealed that it is not possible to obtain root canal walls completely free of debris ${ }^{14,31}$

SEM studies have been proved to allow examination of dentinal tubules with respect to the presence of filling materials ${ }^{6,26,27}$. Complex root canal systems can make it difficult to clean the root canal system efficiently. In the present study, SEM micrographs showed dentinal tubules free of filling material remnants. The apical third presented the smallest number of clean dentinal tubules, compared to the middle root third.

The present work employed $10 \%$ citric acid to remove smear layer ${ }^{23}$ prior to root canal system obturation. Other studies have examined sealer penetration into dentinal tubules after smear layer removal ${ }^{10,19}$. These studies have found a greater penetration of filling materials into dentinal tubules and enhanced material adhesion to the canal walls. Such a mechanical plug may further become a problem during retreatment procedures.

Our results revealed that there was no difference in the number of clean dentinal tubules amongst the different tested solvents, in the middle or apical thirds. This is no consistent with the findings of a previous study, which showed that chloroform was more effective than eucalyptus oil in dissolving root canal sealers ${ }^{25}$. Another study compared chloroform with 18 essential oils, including eucalyptol and orange oil ${ }^{15}$. These studies evaluated the capacity of dissolving sealers using standard ring moulds and gutta percha cone fragments, respectively. These authors found that only chloroform and rectified turpentine oil dissolved gutta-percha completely. The results of the present study were different because SEM was used only to evaluate dentinal tubules regarding the presence of root filling material.

Chloroform, halothane and turpentine oil have been described as cytotoxic solvents ${ }^{1}$. In a recent study, orange oil was found to be more biocompatible than chloroform and eucalypto ${ }^{24}$. In the present study orange oil performed equally to chloroform and eucalyptol. Therefore, orange oil can be recommended as a suitable alternative to those products.

\section{CONCLUSIONS}

During endodontic retreatment of root canals filled with gutta-percha and sealer, orange oil, chloroform and eucalyptol performed equally for removal of the filling material from dentinal tubules, but superior to retreatment without the use of a solvent.

\section{ACKNOWLEDGEMENTS}

This research was supported by FAPERJ (Process \# E26171593-02).

\section{REFERENCES}

1- Barbosa SV, Burkard DH, Spangberg LSW. Cytotoxic effects of gutta-percha solvents. J Endod. 1994;20:6-8.

2- Barletta FB, Lagranha SB. Análisis comparativo in vitro de diferentes técnicas de desobturación de conductos radiculares. Endodoncia. 2002;20:189-96.

3- Carvalho Maciel AC, Scelza MFZ. Efficacy of automated versus hand instrumentation during root canal retreatment: an ex vivo study. Int Endod J. 2006;39:779-84

4- Chohayeb AA. Comparison of conventional root canal obturation techniques with Thermafill obturators. J Endod. 1992; 18:10-2

5- Chutich MJ, Kaminski EJ, Miller DA, Lautenschlager EP. Risk evaluation of gutta-percha solvents in endodontic retreatment. J Endod. 1995;21:236. (AAE-abstract PC 20).

6- Ezzie E, Fleury, A, Solomon E, Spears R, He J. Efficacy of retreatment techniques for a resin-based root canal obturation material. J Endod. 2006;32:341-4.

7- Farge P, Nahas P, Bonin P. In vitro study of a Nd:YAP Laser in endodontic retreatment. J Endod. 1998; 24:359-63.

8- Friedman S, Rotstein I, Shar-Lev S. Bypassing gutta-percha root fillings with an automated device. J Endod. 1989;15:432-7.

9- Friedman S, Stabholz A, Tamse A. Endodontic retreatment-case selection and technique. Part 3. Retreatment techniques. J Endod. 1990;16:543-9.

10- Gettleman BH, Messer HH, ElDeeb ME. Adhesion of sealer cements to dentine with and without the smear layer. J Endod. 1991;17:15-20.

11- Hansen MG. Relative efficiency of solvents used in endodontics. J Endod. 1998;24: 38-40.

12- Hülsmamn M, Bluhm V. Efficacy, cleaning ability and safety of different rotary niti instruments in root canal retreatment. Int Endod J. 2004;37:468-76.

13- Hunter KR, Doblecki W, Pelleu Jr GB. Halothane and eucalyptol as alternatives to chloroform for softening gutta-percha. J Endod. 1991;17:310-1.

14- Imura N, Zuolo ML, Ferreira MOF, Novo NF. Effectiveness of the canal finder and hand instrumentation in removal of gutta-percha root fillings during root canal retreatment. Int Endod J. 1996;29:382-

15- Kaplowitz GJ. Evaluation of the ability of essential oils to dissolve gutta-percha. J Endod 1991;17:448-9.

16- Ladley RW, Campbell AD, Hicks ML, Li SH. Effectiveness of halothane used with ultrasonics or hand instrumentation to remove gutta-percha from the root canal. J Endod. 1991;17:221- 4. 
17- Masiero AV, Barletta FB. Effectiveness of different techniques for removing gutta-percha during retreatment. Int Endod J. $2005 ; 38: 2-7$.

18- Moshonov J, Trope M, Friedman S. Retreatment efficacy 3 months after obturation using glass ionomer cement, zinc oxideeugenol, and epoxy resin sealers. J Endod. 1994;20:90-2.

19- Oksan T, Aktener BO, Sen BH, Tezel H. The penetration of root canal sealers into dentine tubules. A scanning electron microscopic study. Int Endod J. 1993;26:301-5.

20- Oliveira D P, Barbizam JVB, Trope M, Teixeira B. Comparison between gutta-percha and resilon removal using two different techniques in endodontic retreatment. J Endod. 2006;32:362-4.

21- Pécora JD, Costa WF, Filho DS, Sarti SJ. Apresentação de um óleo essencial, obtido de citrus aurantium, eficaz na desintegração do cimento de óxido de zinco-eugenol do interior de canal radicular. Odonto. 1992;1:130-2

22- Sae-Lim V, Rajamanickam I, Lim BK, Lee HL. Effectiveness of ProFile .04 taper rotary instruments in endodontic retreatment. J Endod. 2000;26:100-4.

23- Scelza MFZ, Pierro V, Scelza P, Pereira M. Effect of three different time periods of irrigation with EDTA-T, EDTA, and citric acid on smear layer removal. Oral Surg Med Oral Pathol Oral Radiol Endod. 2004;98:499-503.

24- Scelza MFZ, Oliveira CRL, Carvalho FB, Faria SCR. In vitro evaluation of macrophage viability after incubation in orange oil, eucalyptol and chloroform. Oral Surg Med Oral Pathol Oral Radiol Endod. 2006;102:24-7.

25- Schäfer E, Zandbiglari T. A comparison of effectiveness of chloroform and eucalyptus oil in dissolving root canal sealers. Oral Surg Oral Med Oral Pathol. 2002;93: 611-6.

26- Sen BH, Wesselink PR, Türkün M. The smear layer: a phenomenon in root canal therapy. Int Endod J. 1995;23:141-8.

27- Sen BH, Piskin B, Baran N. The effect of tubular penetration of root canal sealers on dye microleakage. Int Endod J. 1996;29:23-8.

28- Stabholz A, Friedman S. Endodontic retreatment-Case selection and technique. Part 2: Treatment planning for retreatment. J Endod. $1988 ; 14: 607-14$

29- Taintor JF, Ingle JI, Fahid A. Retreatment versus further treatment. Clin Prevent Dent. 1983;5:8-14.

30- Whitworth JM, Boursin EM. Dissolution of root canal sealer cements in volatile solvents. Int Endod J. 2000;33:19-24.

31- Wilcox LR, Krell KV, Madison S, Rittman B. Endodontic retreatment: evaluation of gutta-percha and sealer removal and canal reinstrumentation. J Endod. 1987;13:453-7.

32- Wilcox LR. Endodontic retreatment: ultrasonics and chloroform as the final step in reinstrumentation. J Endod. 1989;15:125-8.

33- Wilcox LR, Juhlin JJ. Endodontic retreatment of thermafill versus laterally condensed Gutta-percha. Int Endod J. 1994;20:115-7. 